\title{
Ultrasound Assessment of Entheses and Correlations Between Disease Activity and Ultrasound Scores in Ankylosing Spondylitis: A Cross Sectional Study
}

\section{HAIQIN XIE}

Peking University Shenzhen Hospital

\section{GENGMIN ZHOU}

Peking University Shenzhen Hospital

\section{BO WEN}

Peking University Shenzhen Hospital HAIYU LUO

Peking University Shenzhen Hospital

\section{YUSEN ZHANG}

Peking University Shenzhen Hospital

\section{QIAN DONG}

U-M: University of Michigan

\section{JIANQIU ZHONG}

Peking University Shenzhen Hospital

JIYANG LV

Peking University Shenzhen Hospital

WEIWEI ZHANG

Peking University Shenzhen Hospital

HENG LV

Peking University Shenzhen Hospital

\section{DESHENG SUN}

Peking University Shenzhen Hospital

Qingwen Wang ( $\square$ wangqingwen_sw@126.com )

Peking University Shenzhen Hospital https://orcid.org/0000-0003-3723-2414

\section{LIU LI}

Peking University Shenzhen Hospital

Research article 
Keywords: Ultrasound, enthesitis, ankylosing spondylitis, disease activity

Posted Date: October 27th, 2020

DOI: https://doi.org/10.21203/rs.3.rs-95578/v1

License: (c) (i) This work is licensed under a Creative Commons Attribution 4.0 International License. Read Full License 


\section{Abstract}

Background: An increasing number of studies have applied ultrasound (US) to evaluate enthesitis in spondyloarthritis. However, there is no clear agreement on which sites should be evaluated for enthesitis. Furthermore, there are different opinions on whether US can monitor disease activity. The objectives of this study were to evaluate the common involvement of entheses and correlations between disease activity and US scores in ankylosing spondylitis (AS).

Methods: A cross-sectional, monocentric, and controlled study was performed. US was used to scan 34 entheses per person and the Madrid sonography enthesitis index (MASEI) score was used. US scores were used to evaluate the elemental lesions of hypoechogenicity, thickness, erosion, calcification, bursitis, and Doppler signal. Disease activity was assessed by Disease Activity Score-C reactive protein (ASDAS$\mathrm{CRP}$ ) and Bath Ankylosing Spondylitis Disease Activity Index (BASDAI).

Results: 104 patients with AS and 50 control subjects were included. A total of 5236 entheses were assessed. Compared with the control subjects, only three entheses - the Achilles tendon (AT), sternoclavicular joint (SCJ), and costochondral joint (CCJ) - showed significant differences in the AS group $(p<0.05)$. Patients with high disease activity (ASDAS-CRP $\geq 2.1$ ) had higher scores than patients with low activity (ASDAS-CRP $<2.1)$ in erosion $(p=0.02)$. Patients who were categorized in very high disease activity (ASDAS-CRP $\geq 3.5$ ) had a higher score in erosion $(p=0.02)$. The erosion score was moderately associated with ASDAS-CRP and BASDAI $(r=0.44, r=0.21)$.

Conclusions: The commonly involved entheses were the AT, SCJ, and CCJ in AS. Erosion occurred more often in patients with disease activity or high activity. Erosion would be more useful for monitoring disease activity in AS.

\section{Background}

Enthesitis is a characteristic sign of ankylosing spondylitis (AS). It has been validated that enthesitis is important for the diagnosis of AS and monitoring disease activity [1]. AS can cause physical damage and disability, declining the patient's quality of life and bringing about a financial burden to both their families and society as a whole [2, 3]. The prevalence of AS ranges from $0.1-0.9 \%$ [4]. Early diagnosis and treatment can decrease the probability of disability and improve the outcome. However, the diagnosis of AS was usually delayed by an average of $6-9$ years after the onset of clinical symptoms $[5,6]$.

X-rays are still the first line of investigation for the evaluation of enthesitis, although the changes may occur in the late phase [7]. Computed tomography (CT) can demonstrate bone erosion, but it is limited by radiation exposure and low resolution for soft tissue. Magnetic resonance imaging (MRI) has been considered more valuable, as it can reveal bone edema and soft tissue swelling. Nonetheless, MRI is limited by its availability and high cost. Additionally, it cannot assess many entheses due to it being a time-consuming process. Ultrasound (US) has many advantages, such as being cheap, portable, nonradioactive, done in real-time, and can be easily compared to the opposite side. It is becoming 
increasingly accepted by rheumatologists as a suitable method. Also, some studies reported that US can evaluate enthesitis for disease diagnosis, even in the early stages of spondyloarthritis $[8,9]$.

Recently, more studies have applied US to evaluate enthesitis in spondyloarthritis, where the main type of spondyloarthritis is AS [8-11]. Nowadays the standardized definition of US enthesitis is in accordance with the definition given by Outcome Measures in Rheumatology (OMERACT) [12]. However, there is no clear agreement on which sites should be evaluated for enthesitis. Most studies have focused on the lower limbs $[11,13,14]$, while some others investigated the upper limbs $[15,16]$. However, few articles pay attention to the anterior chest wall (ACW) [17]. The ACW has been demonstrated as the second most commonly involved site in spondyloarthritis just behind the sacroiliac joint [18]. Furthermore, there are different opinions on whether US can monitor disease activity [19-21]. More studies are needed to assess whether disease activity is correlated with US elemental lesions.

The main objective of the present study was to evaluate the common involvement entheses in AS, including the upper limbs, lower limbs, trunk, and ACW. Second, the correlations between disease activity and US scores were assessed. Further study is needed to determine whether enthesis US can monitor disease activity in AS.

\section{Methods}

\section{Patients and study design.}

This was a cross-sectional study with health control. The study was performed following the Declaration of Helsinki principles and local regulations. The approval was permitted by the ethical committee of Peking University Shenzhen Hospital. All patients and healthy individuals signed informed consent.

Between December 2017 and December 2019, the study finally enrolled 104 patients with AS who fulfilled the modified New York criteria [22]. All the patients were consecutively enrolled from the Department of Rheumatology and Immunology at Peking University Shenzhen Hospital.

The exclusion criteria included the following: a history of joint or ACW surgery; corticoid injection at the enthesis within the last six weeks; peripheral neuropathy; age <18 years; diseases other than AS; and an unwillingness to sign for consent, or did not finish all the examinations or patient-reported outcome measures (PROMs). If patients met one of the above conditions, they were excluded.

\section{Controls.}

Fifty healthy persons were matched with AS patients in age, gender, and body mass index (BMI). They were selected among the hospital workers and healthy volunteers who did not have any symptoms at the entheses, without the diagnosis of spondyloarthritis or family history.

\section{Data collection.}


Data was collected by PROMs, laboratory data, and US assessments.

PROMs and laboratory data. All patients were examined by a qualified rheumatologist. The rheumatologist used PROMs. For each patient, the laboratory tests consisted of $C$ reactive protein (CRP) and human leukocyte antigen B27 (HLA-B27). Disease activity was assessed by Disease Activity ScoreCRP (ASDAS-CRP) and Bath Ankylosing Spondylitis Disease Activity Index (BASDAI). The interval between each examination was less than one week. The ASDAS-CRP value $\left(V_{\text {ASDAS-CRP }}\right)$ indicated the disease activity of AS. When the value was $<1.3$, the disease was inactive. When the value was $1.3 \leq$ $V_{\text {ASDAS-CRP }}<2.1$, the disease activity was low. When the index was $2.1 \leq V_{\text {ASDAS-CRP }}<3.5$, the disease activity was high. When the index was $\geq 3.5$, the disease activity was very high. BASDAI was a selfassessment form to measure disease activity. It had six questions, and each question was scored from 0 to 10 . When the overall score was $\geq 4$, it indicated disease activity. Otherwise, it indicated disease inactivity. A higher score reflected a more active disease.

US assessment. Ultrasonography was performed using Toshiba Aplio 400 equipment with a linear transducer with a frequency of 7-18 $\mathrm{MHz}$ by an experienced sonographer who had taken part in musculoskeletal US for more than five years. All subjects were examined by grey scale and power Doppler ultrasonography. Doppler settings were standard with a pulse repetition frequency of $1000 \mathrm{~Hz}$, low wall filter, and Doppler gain at a level of just below random noise. The sonographer was blinded to clinical information, and people were advised not to talk with the US examiner. US was used to evaluate 34 entheses in the upper limbs, lower limbs, trunk, and ACW. The upper limbs contained three bilateral entheses: common extensor tendon (CET), common flexor tendon (CFT), and supraspinatus tendon (SST). The lower limbs were comprised of seven bilateral entheses: quadriceps tendon (QT), proximal patella tendon (PPT), distal patella tendon (DPT), lateral collateral ligament ( $\mathrm{LCL}$ ) on the lateral femoral condyle, medial collateral ligament (MCL) on the medial femoral condyle, Achilles tendon (AT) on the calcaneus, and plantar fascia (PF). The trunk consisted of two entheses: the bilateral anterosuperior iliac spine (ASIS) and the single pubic symphysis (PS). The ACW included three entheses: bilateral sternoclavicular joint (SCJ), single manubriosternal junction (MSJ), and costochondral joint (CCJ), in which the CCJ included eight bilateral entheses from the $2^{\text {nd }}$ to $5^{\text {th }}$ ribs. Each site was scanned in both longitudinal and transverse planes and the images were saved. Examinations of the SST, CET, and CFT were performed in a sitting position. The QT, PPT, DPT, LCL, and MCL were assessed with the individual in the supine position with knee flexion at $30-60^{\circ}$. The AT and PF were examined in a prone position with the feet hanging off of the bedside. The remaining entheses were evaluated in a supine position with the elbow contacting the body. All the standardized examinations were followed by the European Society of Musculoskeletal Radiology (ESSR).

US definition. Elemental US lesions of enthesitis were as follows (Figure 1): 『hypoechogenicity with lack

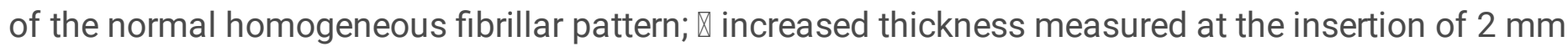
near the bone cortex, and the data followed Glasgow Ultrasound Enthesitis Scoring System (GUESS) [11]; $\nabla$ erosion with cortical breakage with contour defect in both longitudinal and transverse planes; $\mathbb{Z}$ calcification: hyperechoic foci or bony prominence at the end of the bone contour, with or without 
acoustic shadow; $\otimes$ bursitis: the locations of bursitis consisted of suprapatellar, infrapatellar, and retrocalcaneal bursas, with the normal anteroposterior diameter less than $5 \mathrm{~mm}, 2 \mathrm{~mm}$, and $3 \mathrm{~mm}$, respectively [23]; and $\triangle$ Doppler signal at the insertion $2 \mathrm{~mm}$ near the bone surface with the tendon or ligament at a relaxation position. Enthesis US scores followed the MASEl: calcification (0-3), erosion ( 0 or $3)$, Doppler signal (0 or 3$)$, hypoechogenicity (0-1), increased thickness (0-1), and bursitis (0-1). The US images were read by two sonographers. If there was a difference in opinion, a third sonographer would help to make a decision. A definition of enthesis US positive was at least one abnormal enthesis in one site. Acute echogenicity consisted of hypoechogenicity, increased thickness, bursitis, and Doppler signal. Chronic echogenicity included erosion and calcification.

\section{Statistical analysis.}

The quantitative data were shown by mean \pm standard deviation (SD), and the qualitative data were shown by percentages. A Student's $t$ test or Mann-Whitney $U$ test was used for the quantitative analysis. Chi-square test (or Fisher exact test when appropriate) was used for the categorical data. According to Spearman's correlation coefficient, correlations between disease activity and US scores were obtained. Values of $p<0.05$ were significant. SPSS version 23.0 software (IBM, Armonk, NY, USA) was used for all data analyses.

\section{Results}

\section{Demographic and clinical data}

With a total of 247 potential AS patients, the study finally enrolled 104 patients with AS in the end (Figure 2). In addition, 50 control subjects were included. There were 34 entheses by US assessment in each person (Figure 3a). Thus, a total of 5236 entheses were evaluated, consisting of 3536 sites in patients with AS and 1700 sites in the controls. The AS and control groups matched in age, gender, and BMI. The demographic and clinical data were summarized in Table 1. Most patients with AS were male $(71.15 \%)$. $94.23 \%$ of patients were HLA-B27 positive.

\section{The common involvement entheses in AS}

There were 15 different sites within a total of 34 entheses in each person. US scanning time was 40-50 min per person. The rates of enthesis US positive in the AS and control groups were $91.35 \%$ and $84.00 \%$, respectively. There was no statistical difference between the two groups $(p=0.17)$. The sequences of involvement entheses from high to low were AT $>$ QT $>$ SCJ $>$ DPT $>$ CET $=$ SST $>$ CCJ $>$ MSJ $>$ PPT $=$ PF $>$ ASIS $>$ CFT $>$ PS $=$ MCL $>$ LCL (Table 2). However, compared with the control group, only the three entheses of AT, SCJ, and CCJ showed significant differences in the AS group $(p<0.05)$, as seen in Figure 3b. The AT and ACW were the common involvement sites in AS.

\section{Comparing enthesis US scores in different groups assessed by ASDAS-CRP and BASDAI}


In contrast to the control group, the enthesis US scores of MASEl, hypoechogenicity, thickness, erosion, Doppler signal, and acute and chronic echogenicity were higher, except for calcification and bursitis in the AS group, as presented in Table 3 .

The enthesis US scores did not show significant differences between patients with disease activity (ASDAS-CRP $\geq 1.3$ ) and patients with disease inactivity (ASDAS-CRP < 1.3), as seen in Table $\mathrm{S} 1$ (the supplemental file). In addition, patients with high disease activity (ASDAS-CRP $\geq 2.1$ ) had higher scores compared to patients with low activity (ASDAS-CRP $<2.1)$ in erosion and bursitis $(p=0.02, p=0.04)$. Patients who were categorized as having very high disease activity (ASDAS-CRP $\geq 3.5$ ) had a higher score in erosion $(p=0.02)$.

\section{Correlations between disease activity and US scores in AS}

The disease activity was assessed by ASDAS-CRP and BASDAl, and the erosion score was associated with both of them (Figure 3c). However, the calcification score did not correlate with them. Moreover, all of the enthesis US scores except the thickness score had significant associations with the ASDAS-CRP. The range of correlation coefficient was from 0.22 to 0.44 (Figures S1 and S2 in the supplemental file).

\section{Discussion}

It has been validated that US is a useful tool for enthesitis in AS, especially within the last 20 years. An increasing number of rheumatologists prefer to assess peripheral enthesitis by US, which has the advantages of being readily available, inexpensive, and non-radioactive, while also exhibiting the benefits of having high resolution and bedside convenience. To disseminate this technique in daily work, the standardization of enthesis US should be considered, which would be helpful for further multicenter studies. An international group of OMERACT US experts was formed in 2005. This group aimed to standardize the definition of US elemental lesions for enthesitis [24]. However, there was no determined consensus about which sites should be examined.

The authors observed a total of 5236 entheses in the present study. So far, it was the largest number of sites. More entheseal areas were evaluated and more information was gathered. In the present study, the entheses included the upper limbs, lower limbs, trunk, and ACW, whereas most studies have only focused on the upper and lower limbs [13-15]. The findings of the present study have shown that the three entheses of AT, SCJ, and CCJ were more common in the AS group compared to the control group. The SCJ and CCJ belonged to the ACW, suggesting that enthesis US should assess the sites of the ACW. Furthermore, several studies reported that the rate of ACW involvement was $30-50 \%$ in spondyloarthritis $[25,26]$, and an article from the DESIR cohort revealed $44 \%$ in clinical involvement with the ACW in early spondyloarthritis [27]. Therefore, the ACW was also observed in addition to the upper and lower limbs. The authors' previous studies found that the ACW sites were the common entheses in AS by US assessment. Thus, the ACW should be considered to evaluate enthesitis in patients with AS. 
Monitoring disease activity remains a challenge in AS, because each method is not fully evaluable. In clinical practice, there are a lot of methods for disease activity assessment, including physical examination, laboratory tests (CRP), composite index (BASDAI or ASDAS), or imaging examinations (Xrays, CT, MRI, or US). US has been proven to be a valuable tool for monitoring disease activity and therapeutic effect evaluation $[12,20,28]$. However, one study from the DESIR cohort found that US could not be helpful for monitoring disease activity in 402 patients with spondyloarthritis [21]. Therefore, further studies still need to be conducted to demonstrate the association between US lesions and disease activity. Patients with high disease activity (ASDAS-CRP $\geq 2.1$ ) or very high disease activity (ASDAS-CRP $\geq 3.5$ ) had a higher score in erosion. It represented that erosion could occur more often in patients with disease activity or high activity. In particular, erosion seems to be an indicator for enthesis US in disease activity. De Miguel et al. reported that Achilles erosion had a significant association with objective disease activity in spondyloarthritis [29]. In addition, there was no significant difference in the calcification score between the AS and control groups in the results of the present study. This may be attributable to repeated biological force or aging, which can be seen in normal people [30,31].

Calcification, ossification, and enthesophyte were sometimes shown as the same in US images, making it difficult to differentiate between them. To simplify the description, ossification and enthesophyte were also considered as calcification, as several other reports have made the same decision [24, 32].

Even so, there were still some limitations in the present study. First, the included patients were all inpatients, and most of them were male. As such, there were selection and gender biases. More female patients should have been recruited from the clinics. Second, the disease activity index did not include physical examination because of the low sensitivity and specificity. Third, US scanning was time consuming. Many sites throughout the entire body were investigated for enthesitis to find which entheses were more involved. The next step simplified the entheses.

\section{Conclusions}

In conclusion, the common involvement entheses were the AT, SCJ, and CCJ in patients with AS, which suggested that the AT and ACW should be evaluated by enthesis US. Erosion occurred more often in patients with disease activity or high activity. More research is needed to determine if erosion can be implemented to monitor disease activity in AS.

\section{Abbreviations}

US: ultrasound; AS: ankylosing spondylitis; MASEl: Madrid sonography enthesitis index; ASDAS-CRP: ankylosing spondylitis disease activity score- $\mathrm{C}$ reactive protein; BASDAl: bath ankylosing spondylitis disease activity index; AT: Achilles tendon; QT: quadriceps tendon; SCJ: sternoclavicular joint; DPT: distal patella tendon; CET: common extensor tendon; SST: supraspinatus tendon; CCJ: costochondral joint; MSJ: manubriosternal junction; PPT: proximal patella tendon; PF: plantar fascia; ASIS: anterosuperior iliac spine; CFT: common flexor tendon; PS: pubic symphysis; MCL: medial collateral ligament; LCL: lateral collateral ligament; ACW: anterior chest wall; GUESS: Glasgow Ultrasound Enthesitis Scoring 
System; SD: standard deviation; ESSR: European Society of Musculoskeletal Radiology; CT: computed tomography; MRI: magnetic resonance imaging; OMERACT: Outcome Measures in Rheumatology; PROMs: patient-reported outcome measures; BMI: body mass index; HLA-B27: human leukocyte antigen B27.

\section{Declarations}

Ethics approval: The study was approved by the Ethics Committee of Peking University Shenzhen Hospital, with approval ID 2020030.

Patient consent: Not applicable.

Availability of data and materials: The datasets used and analyzed during the current study were available from the corresponding authors upon reasonable request.

Competing interests: The authors declare that they have no competing interests.

Funding: This study was supported by the Health and Family Planning Commission of Shenzhen Municipality in China (grant no. SZSM201512026), the Science Technology and Innovation Commission of Shenzhen Municipality in China (grant no. JCYJ20170413100222613 and JCYJ20170307112009204), the Natural Science Foundation of Guangdong Province (grant no. 2019A1515011112), and the National Natural Science Foundation of China (grant no. 81974253).

\section{Author contributions}

QW and LL conceived and designed the study. QD and $\mathrm{YZ}$ read the ultrasound images. $\mathrm{HL}$ did the ultrasound examination. GZ asked about patient-reported outcome measures and JL extracted the clinical data from the medical files in the information system. WZ and JZ extracted data from the laboratory system. HX and BW wrote the paper. HL and DS analyzed the data. All the authors have read and approved the manuscript.

\section{Acknowledgements}

We would like to thank the participants in our study. We are very grateful for the engineers of the medical information system.

\section{Author details}

${ }^{1}$ Department of Ultrasound, Peking University Shenzhen Hospital, Shenzhen, Guangdong Province, China;

${ }^{2}$ Department of Rheumatology and Immunology, Peking University Shenzhen Hospital, Shenzhen, Guangdong Province, China; ${ }^{3}$ Department of Radiology, University of Michigan, Ann Arbor, Michigan, USA.

\section{References}


1. Amor B, Dougados M, Mijiyawa M: Criteria of the classification of spondylarthropathies. Rev Rhum Mal Osteoartic 1990, 57(2):85-89.

2. Palla I, Trieste L, Tani C, Talarico R, Cortesi PA, Mosca M, Turchetti G: A systematic literature review of the economic impact of ankylosing spondylitis. Clin Exp Rheumato/ 2012, 30(4 Suppl 73):S136-141.

3. Ward MM: Functional disability predicts total costs in patients with ankylosing spondylitis. Arthritis Rheum 2002, 46(1):223-231.

4. Zhao J, Huang C, Huang H, Pan JK, Zeng LF, Luo MH, Liang GH, Yang WY, Liu J: Prevalence of ankylosing spondylitis in a Chinese population: a systematic review and meta-analysis. Rheumatol Int 2020, 40(6):859-872.

5. Feldtkeller E, Khan MA, van der Heijde D, van der Linden S, Braun J: Age at disease onset and diagnosis delay in HLA-B27 negative vs. positive patients with ankylosing spondylitis. Rheumatol Int 2003, 23(2):61-66.

6. Collantes E, Zarco P, Munoz E, Juanola X, Mulero J, Fernandez-Sueiro JL, Torre-Alonso JC, Gratacos $\mathrm{J}$, Gonzalez C, Batlle E et al: Disease pattern of spondyloarthropathies in Spain: description of the first national registry (REGISPONSER) extended report. Rheumatology (Oxford) 2007, 46(8):13091315.

7. Heuft-Dorenbosch L, Spoorenberg A, van Tubergen A, Landewe R, van ver Tempel H, Mielants $H$, Dougados M, van der Heijde D: Assessment of enthesitis in ankylosing spondylitis. Ann Rheum Dis 2003, 62(2):127-132.

8. de Miguel E, Munoz-Fernandez S, Castillo C, Cobo-lbanez T, Martin-Mola E: Diagnostic accuracy of enthesis ultrasound in the diagnosis of early spondyloarthritis. Ann Rheum Dis 2011, 70(3):434-439.

9. Fujikawa K, Kawashiri SY, Endo Y, Mizokami A, Tsukada T, Mine M, Uetani M, Kawakami A: Diagnostic efficacy of ultrasound detection of enthesitis in peripheral spondyloarthritis. Mod Rheumatol 2019:1-7.

10. Sakellariou G, Iagnocco A, Delle Sedie A, Riente L, Filippucci E, Montecucco C: Ultrasonographic evaluation of entheses in patients with spondyloarthritis: a systematic literature review. Clin Exp Rheumatol 2014, 32(6):969-978.

11. Balint PV, Kane D, Wilson H, Mclnnes IB, Sturrock RD: Ultrasonography of entheseal insertions in the lower limb in spondyloarthropathy. Ann Rheum Dis 2002, 61(10):905-910.

12. Falcao S, Castillo-Gallego C, Peiteado D, Branco J, Martin Mola E, de Miguel E: Can we use enthesis ultrasound as an outcome measure of disease activity in spondyloarthritis? A study at the Achilles level. Rheumatology (Oxford) 2015, 54(9):1557-1562.

13. Vahidfar S, Sunar I, Ataman S, Yilmaz G, Azarabadi JM, Bolukbasi A: Ultrasonographic evaluation of Achilles tendon: Is there any difference between ankylosing spondylitis, non-radiographic axial spondyloarthropathy and controls? Int J Rheum Dis 2020, 23(4):511-519.

14. Alcalde M, Acebes JC, Cruz M, Gonzalez-Hombrado L, Herrero-Beaumont G, Sanchez-Pernaute O: A sonographic enthesitic index of lower limbs is a valuable tool in the assessment of ankylosing spondylitis. Ann Rheum Dis 2007, 66(8):1015-1019. 
15. Genc H, Cakit BD, Tuncbilek I, Erdem HR: Ultrasonographic evaluation of tendons and enthesal sites in rheumatoid arthritis: comparison with ankylosing spondylitis and healthy subjects. Clin Rheumatol 2005, 24(3):272-277.

16. D'Agostino M A, Aegerter P, Jousse-Joulin S, Chary-Valckenaere I, Lecoq B, Gaudin P, Brault I, Schmitz J, Dehaut FX, Le Parc JM et al: How to evaluate and improve the reliability of power Doppler ultrasonography for assessing enthesitis in spondylarthritis. Arthritis Rheum 2009, 61(1):61-69.

17. Verhoeven F, Guillot X, Godfrin-Valnet M, Prati C, Wendling D: Ultrasonographic evaluation of the anterior chest wall in spondyloarthritis: a prospective and controlled study. J Rheumato/2015, 42(1):87-92.

18. Althoff CE, Sieper J, Song IH, Weiss A, Diekhoff T, Haibel H, Hamm B, Hermann KG: Comparison of Clinical Examination versus Whole-body Magnetic Resonance Imaging of Enthesitis in Patients with Early Axial Spondyloarthritis during 3 Years of Continuous Etanercept Treatment. J Rheumato/2016, 43(3):618-624.

19. Hu Z, Xu M, Wang Q, Qi J, Lv Q, Gu J: Colour Doppler ultrasonography can be used to detect the changes of sacroiliitis and peripheral enthesitis in patients with ankylosing spondylitis during adalimumab treatment. Clin Exp Rheumato/2015, 33(6):844-850.

20. Ruta S, Acosta Felquer ML, Rosa J, Navarta DA, Garcia Monaco R, Soriano ER: Responsiveness to therapy change of a global ultrasound assessment in spondyloarthritis patients. Clin Rheumatol 2015, 34(1):125-132.

21. Ruyssen-Witrand A, Jamard B, Cantagrel A, Nigon D, Loeuille D, Degboe Y, Constantin A: Relationships between ultrasound enthesitis, disease activity and axial radiographic structural changes in patients with early spondyloarthritis: data from DESIR cohort. RMD Open 2017, 3(2):e000482.

22. van der Linden $S$, Valkenburg HA, Cats A: Evaluation of diagnostic criteria for ankylosing spondylitis. A proposal for modification of the New York criteria. Arthritis Rheum 1984, 27(4):361-368.

23. Bianchi S, Baert AL, Abdelwahab IF, Derchi LE, Martinoli C, Rizzatto G, Valle M, Zamorani MP: Ultrasound of the Musculoskeletal System: Springer Berlin Heidelberg; 2007.

24. Balint PV, Terslev L, Aegerter P, Bruyn GAW, Chary-Valckenaere I, Gandjbakhch F, lagnocco A, JousseJoulin S, Moller I, Naredo E et al: Reliability of a consensus-based ultrasound definition and scoring for enthesitis in spondyloarthritis and psoriatic arthritis: an OMERACT US initiative. Ann Rheum Dis 2018, 77(12):1730-1735.

25. Fournie B, Boutes A, Dromer C, Sixou L, Le Guennec P, Granel J, Railhac JJ: Prospective study of anterior chest wall involvement in ankylosing spondylitis and psoriatic arthritis. Rev Rhum Engl Ed 1997, 64(1):22-25.

26. Elhai M, Paternotte S, Burki V, Durnez A, Fabreguet I, Koumakis E, Meyer M, Payet J, Roure F, Dougados $\mathrm{M}$ et al: Clinical characteristics of anterior chest wall pain in spondyloarthritis: an analysis of 275 patients. Joint Bone Spine 2012, 79(5):476-481. 
27. Wendling D, Prati C, Demattei C, Loeuille D, Richette P, Dougados M: Anterior chest wall pain in recent inflammatory back pain suggestive of spondyloarthritis. data from the DESIR cohort. $J$ Rheumatol 2013, 40(7):1148-1152.

28. Wang CH, Feng Y, Ren Z, Yang X, Jia JF, Rong MY, Li XY, Wu ZB: Performance of ultrasound to monitor Achilles enthesitis in patients with ankylosing spondylitis during TNF-a antagonist therapy. Clin Rheumatol 2015, 34(6):1073-1078.

29. de Miguel E, Falcao S, Castillo C, Plasencia C, Garcia M, Branco JC, Martin-Mola E: Enthesis erosion in spondyloarthritis is not a persistent structural lesion. Ann Rheum Dis 2011, 70(11):2008-2010.

30. Apostolakos J, Durant TJ, Dwyer CR, Russell RP, Weinreb JH, Alaee F, Beitzel K, McCarthy MB, Cote MP, Mazzocca AD: The enthesis: a review of the tendon-to-bone insertion. Muscles Ligaments Tendons J 2014, 4(3):333-342.

31. Kamo K, Yahiro K: Incidence and risk factors of calcaneal enthesophytes in spondyloarthritis and trauma patients. Mod Rheumatol 2016, 26(4):598-600.

32. de Miguel E, Cobo T, Munoz-Fernandez S, Naredo E, Uson J, Acebes JC, Andreu JL, Martin-Mola E: Validity of enthesis ultrasound assessment in spondyloarthropathy. Ann Rheum Dis 2009, 68(2):169174.

\section{Tables}

Table 1

Demographic and clinical data

\begin{tabular}{|lll|}
\hline & $\begin{array}{l}\text { AS group } \\
(\boldsymbol{n}=104)\end{array}$ & $\begin{array}{l}\text { Control group } \\
(\boldsymbol{n}=\mathbf{5 0})\end{array}$ \\
\hline Female/male & $30 / 74$ & $8 / 42$ \\
\hline Age, years (mean \pm SD) & $33.34 \pm 8.32$ & $33.44 \pm 8.52$ \\
\hline BMI (mean \pm SD) & $22.73 \pm 1.87$ & $22.69 \pm 1.87$ \\
\hline Disease duration, years (mean \pm SD) & $8.00 \pm 6.66$ & - \\
\hline HLA-B27 (\%) & 94.23 & - \\
\hline CRP, mg/L (mean \pm SD) & $16.33 \pm 21.67$ & - \\
\hline BASDAI (mean \pm SD) & $2.73 \pm 1.68$ & - \\
\hline ASDAS-CRP (mean \pm SD) & $2.52 \pm 0.93$ & - \\
\hline $\begin{array}{l}\text { AS, ankylosing spondylitis; SD, standard deviation; BMl, body mass index; HLA-B27, human leukocyte } \\
\text { antigen B27; CRP, C reactive protein; BASDAl, Bath Ankylosing Spondylitis Disease Activity Index; } \\
\text { ASDAS-CRP, Ankylosing Spondylitis Disease Activity Score-CRP; -, not available. }\end{array}$ \\
\hline
\end{tabular}


Table 2

Prevalence of enthesis US positive in each site between AS and control groups

\begin{tabular}{|c|c|c|c|}
\hline & $\begin{array}{l}\text { AS group } \\
(n=104)\end{array}$ & $\begin{array}{l}\text { Control group } \\
(n=50)\end{array}$ & $p$ \\
\hline AT & $73(70)$ & $24(48)$ & $0.01^{\star}$ \\
\hline QT & $53(51)$ & $26(52)$ & 0.90 \\
\hline SCJ & $34(33)$ & $4(8)$ & $0.00^{\star}$ \\
\hline DPT & $18(17)$ & $8(16)$ & 0.84 \\
\hline CET & $14(13)$ & $4(8)$ & 0.32 \\
\hline SST & $14(13)$ & $2(4)$ & 0.07 \\
\hline CCJ & $12(11)$ & $0(0)$ & $0.01^{*}$ \\
\hline MSJ & $8(8)$ & $4(8)$ & 1.00 \\
\hline PPT & $6(6)$ & $2(4)$ & 0.18 \\
\hline PF & $6(6)$ & $0(0)$ & 0.18 \\
\hline ASIS & $3(3)$ & $0(0)$ & 0.55 \\
\hline CFT & $2(2)$ & $0(0)$ & 1.00 \\
\hline PS & $1(1)$ & $0(0)$ & 1.00 \\
\hline MCL & $1(1)$ & $0(0)$ & 1.00 \\
\hline LCL & $0(0)$ & $0(0)$ & - \\
\hline \multicolumn{4}{|c|}{$\begin{array}{l}\text { US, ultrasound; AS, ankylosing spondylitis; AT, Achilles tendon; QT, quadriceps tendon; SCJ, } \\
\text { sternoclavicular joint; DPT, distal patella tendon; CET, common extensor tendon; SST, supraspinatus } \\
\text { tendon; CCJ, costochondral joint; MSJ, manubriosternal junction; PPT, proximal patella tendon; PF, } \\
\text { plantar fascia; ASIS, anterosuperior iliac spine; CFT, common flexor tendon; PS, pubic symphysis; } \\
\text { MCL, medial collateral ligament; LCL, lateral collateral ligament; -, not available. }\end{array}$} \\
\hline
\end{tabular}


Table 3

US scores and each lesion in AS and control groups

\begin{tabular}{|llll|}
\hline & $\begin{array}{l}\text { AS group } \\
(n=104)\end{array}$ & $\begin{array}{l}\text { Control group } \\
(n=50)\end{array}$ & $P$ \\
\hline MASEl score & $10.39 \pm 11.06$ & $3.96 \pm 3.54$ & $<0.01^{*}$ \\
\hline Hypoechogenicity & $1.31 \pm 1.86$ & $0.32 \pm 0.68$ & $<0.01^{*}$ \\
\hline Thickness & $0.98 \pm 1.77$ & $0.20 \pm 0.57$ & $<0.01^{*}$ \\
\hline Erosion & $1.36 \pm 2.92$ & $0.00 \pm 0.00$ & $<0.01^{*}$ \\
\hline Calcification & $3.48 \pm 3.99$ & $2.68 \pm 2.84$ & 0.29 \\
\hline Bursitis & $0.79 \pm 1.17$ & $0.76 \pm 0.92$ & 0.75 \\
\hline Doppler signal & $2.48 \pm 3.61$ & $0.00 \pm 0.00$ & $<0.01^{*}$ \\
\hline Acute echogenicity & $5.56 \pm 7.10$ & $1.28 \pm 1.44$ & $<0.01^{*}$ \\
\hline Chronic echogenicity & $4.84 \pm 4.90$ & $2.68 \pm 2.84$ & $<0.01^{*}$ \\
\hline US, ultrasound; MASEl, Madrid Sonography Enthesitis Index; AS, ankylosing spondylitis. & \\
\hline * $p<0.01$ between the AS group and the control group. & \\
\hline
\end{tabular}

\section{Additional Material}

Additional file Table S1: Comparing enthesis US scores in different groups assessed by ASDAS-CRP and BASDAI.

Additional file Figure S1: Correlations between ASDAS-CRP and US scores. US scores included Madrid sonography enthesitis index (MASEI) score (A), hypoechogenicity (B), thickness (C), erosion (D), calcification $(E)$, bursitis $(F)$, Doppler signal $(G)$, acute echogenicity $(H)$, and chronic echogenicity $(I)$.

Additional file Figure S2: Correlations between BASDAI and US scores. US scores included Madrid sonography enthesitis index (MASEI) score (A), hypoechogenicity (B), thickness (C), erosion (D), calcification $(E)$, bursitis $(F)$, Doppler signal $(G)$, acute echogenicity $(H)$, and chronic echogenicity $(I)$.

\section{Figures}



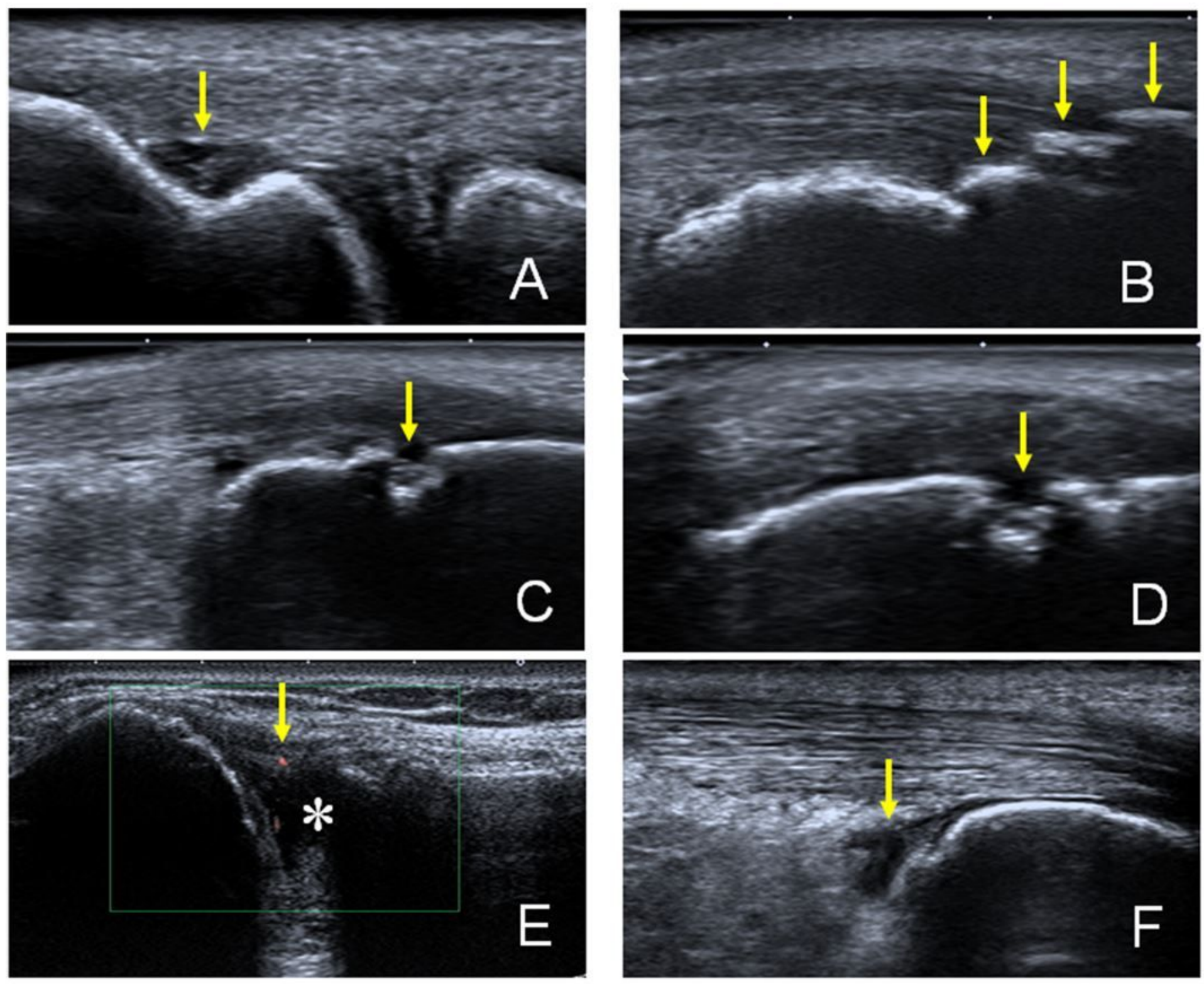

\section{Figure 1}

Ultrasonographic appearance of enthesis lesions. (A) Hypoechogenicity in common extensor tendon, longitudinal plane (arrow). (B) Calcification score 3 (arrow) and thickness in Achilles tendon, longitudinal plane. (C) and (D) Erosion in Achilles tendon (arrow), (C) longitudinal plane and (D) short view. (E) Doppler in sternoclavicular joint (arrow), longitudinal plane, and effusion in the joint (asterisk). (F) Bursitis in retrocalcaneal bursa, longitudinal plane (arrow). 


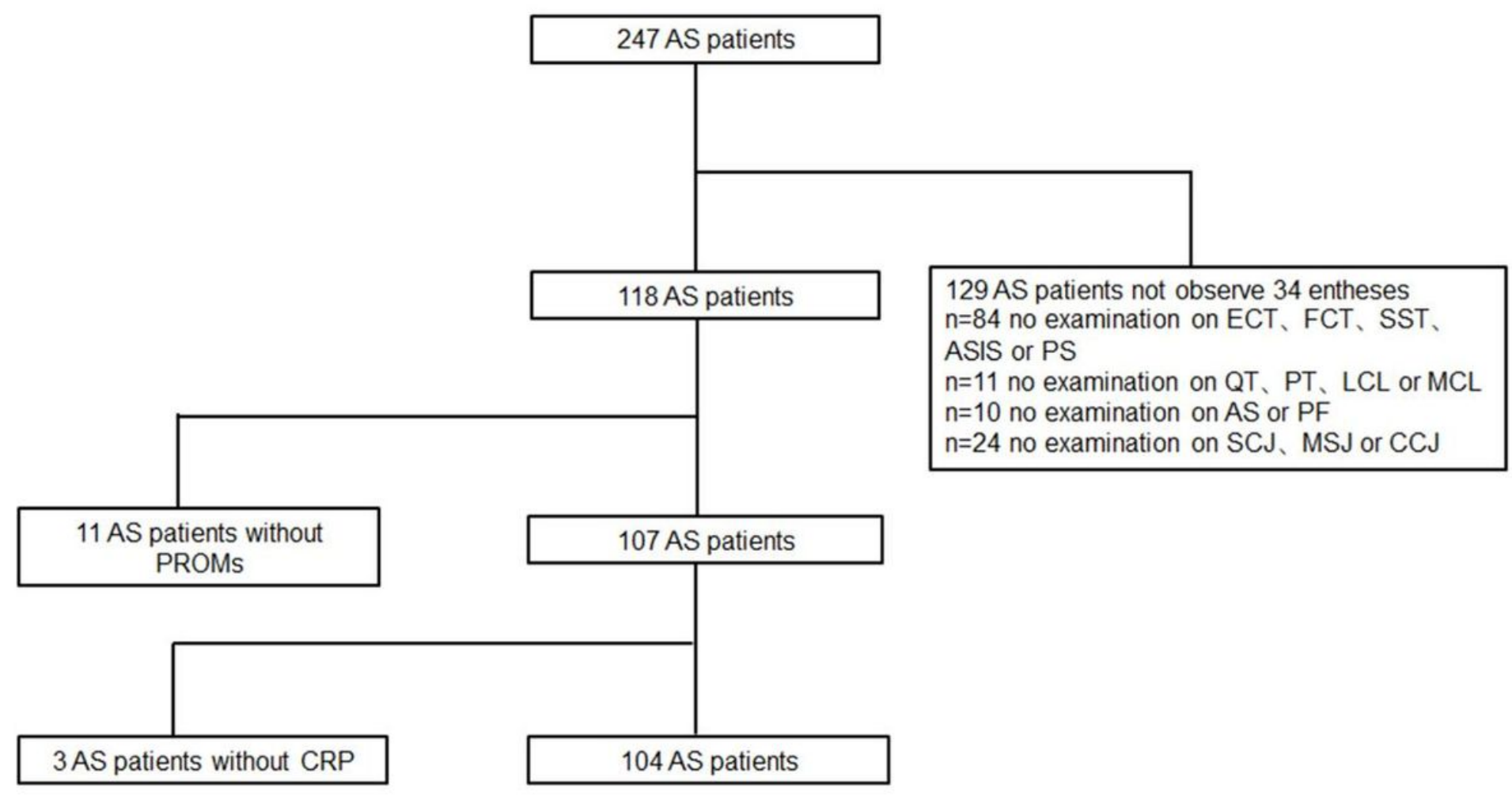

\section{Figure 2}

Flow chart of patients in AS. All of 247 patients, 129 patients did not observe 34 entheses, 11 patients without PROMs and 3 patients without CRP. 

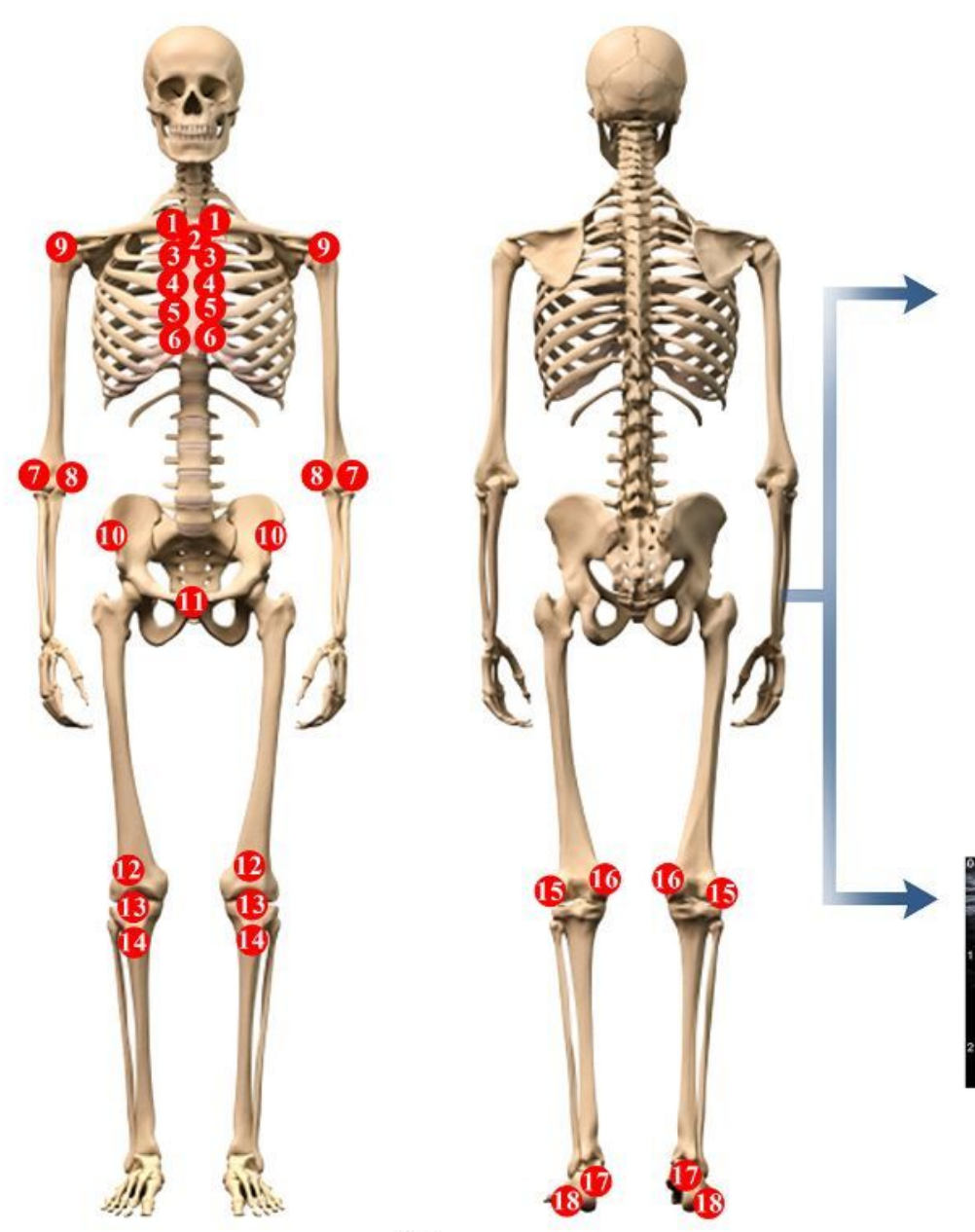
SCJ, CCJ and AT were commonly involved in AS
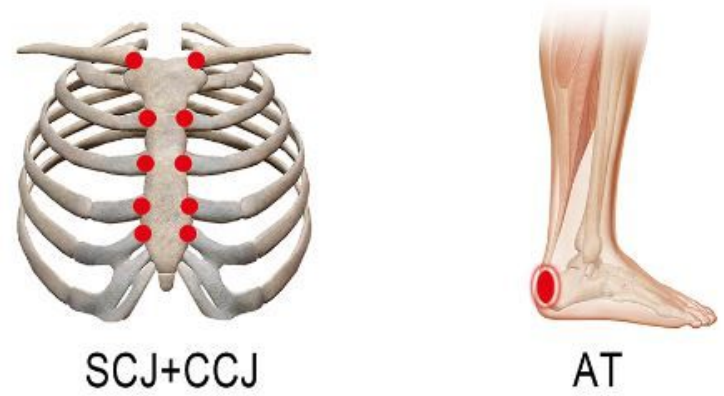

(b)

Erosion would be useful for monitoring disease activity in AS

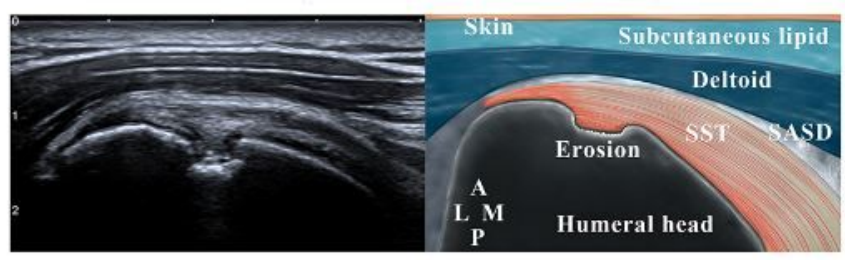

SSC erosion

(c)

(a)

Figure 3

Ultrasound (US) scanning and findings. (a) US scanned 4 entheses per person. US findings were shown in (b) and (c). (b) The commonly involved entheses were AT, SCJ, and CCJ in AS. (c) Erosion would be more

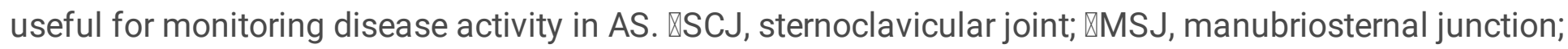
$\varangle$ 2nd CCJ, second costochondral joint; $\otimes$ 3rd CCJ, third costochondral joint; $\varangle 4$ th CCJ, fourth costochondral joint; $₫ 5$ th CCJ, fifth costochondral joint; $₫ \mathrm{CET}$, common extensor tendon; $\otimes C F T$, common

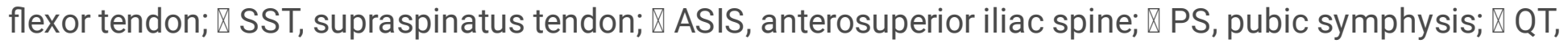

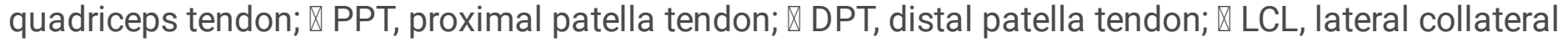

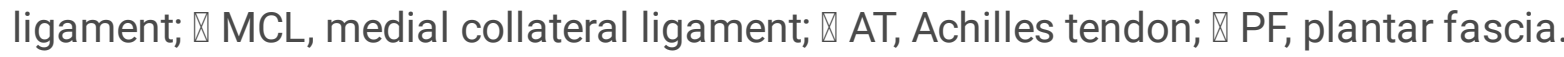

\section{Supplementary Files}

This is a list of supplementary files associated with this preprint. Click to download.

- Supplementaryfile.docx 
Page 18/18 